\title{
An exploration study to find important factors influencing on brand in car accessory market
}

\author{
Naser Azad, Seyed Mohsen Seyed Aliakbar, Majid Tavassoli and Mohammad Reza Jafar Zadeh
}

Department of Management, Islamic Azad University, South Tehran Branch, Tehran, Iran

\begin{tabular}{l}
\hline C H R O N I C L E \\
\hline Article history: \\
Received May 12, 2013 \\
Received in revised format \\
25 June 2013 \\
Accepted 27 June 2013 \\
Available online \\
July 12013 \\
\hline Keywords: \\
Car accessory \\
Factor analysis \\
Brand image
\end{tabular}
A B S T R A C T

\begin{abstract}
Supplying car accessory is one of the most important growing industries in the world. Every year, millions of cars are produced and people need to have the access to necessary car accessory. In this paper, we present an exploration study to detect important factors influencing car accessory market. The proposed study designs a questionnaire in Likert scale consists of 16 questions, distributes it among 200 experts and analyses it using factor analysis. Cronbach alpha and Kaiser-Meyer-Olkin Measure of Sampling Adequacy are calculated as 0.823 and 0.863 , which validate the overall questionnaire. The results indicate that there are three influencing factors including brand capability, brand characteristics and consumers' believe.
\end{abstract}

\section{Introduction}

Building a brand has been a concern in product development and it plays essential role on marketing planning. Brand image, as part of brand characteristics, is another important component of building competitive brand in today's society. During the past few years, there have been various studies on learning the effect of brand image on product development. Jo et al. (2003), for instance, investigated the shifting effects of brand image against lower quality countries-of-origin in global manufacturing. They reported that brands with high familiarity and high quality reputations or strong brands have much smaller perceived-quality discounting for lower quality countries-of-origin than brands with mediocre familiarity and weak brands. Rindell et al. (2011) investigated the role of brand images in consumer practices for uncovering brand strength and suggested practices as an additional unit of analysis for understanding brand strength based on image. Roth (1995) studied the effects of culture and socioeconomics on the performance of global brand image strategies. Banerjee (2004) presented a brand share prediction model based on several disparate sources of data in an empirical model of detergent choice in Mumbai, India.

*Corresponding author.

E-mail address:dr.naserazad@yahoo.com (N. Azad) 
Kort et al. (2006) developed a model of a fashion designer's challenge of keeping brand image in the face of short-term profit opportunities through expanded sales that risk brand dilution in the longerrun. Base on this study, it is worth incurring short-term losses while increasing the brand's reputation, even if starting a new brand name from scratch is not optimal.

Sääksjärvi and Samiee (2011) examined the relationships among brand identity, brand image, and brand preference in the context of cyber and offline-based extension retail brands over time. They examined a conceptual model with survey data collected over three time periods and found out that offline-based extension brands had an advantage over cyber brands when it came to translating a brand identity into a successful brand image, especially in the early Internet stages. Bian and Moutinho (2011) investigated the role of brand image, product involvement, and knowledge in explaining consumer buying behaviour of counterfeits in terms of either direct and indirect effects. Chien et al. (2011) hypothesized that in the event of a sponsorship portfolio, the source of image transfer could be composite, and brand image association could depend on the perceived fit between sponsorships. Hsieh and $\mathrm{Li}$ (2008) investigated the moderating impact of brand image on public relations perception and customer loyalty. They reported that consumers' perception of an organisation's PR practice was an antecedent of loyalty. The effect of public relations perception (PRP) on customer loyalty was stronger and more significant when the brand image was favourable.

Prayag (2010) assessed the brand image of Cape Town as a tourist destination using a progressive technique of unstructured and structured techniques such as word association and free association. They highlighted the strengths and weaknesses of techniques such as word association and free association. The results indicated that some image attributes could not always sufficiently differentiate the brand from its competitors.

Arslan and Altuna (2010) investigated the effect of brand extensions on product brand image. They studied the effects of fit, familiarity, perceived quality and attitude towards the brand on product brand image after an extension. They also examined whether the product image of a brand could be diluted as a result of brand extension. They reported that brand extensions could influence the product brand image negatively, whereas the fit between the parent and extension brands could decrease the negative effect.

Matthiesen and Phau (2010) examined whether brand perceptions differ across channel members of luxury brands using the buyer-seller exchange situation model and reported that brand perceptions had been differed across channel members. Hu et al. (2012) examined the effect of functional and symbolic image congruity in Chinese consumers' brand preferences in the auto market, and the effect of brand familiarity in moderating the relationship between brand image congruity and consumers' preferences. Ogba and Tan (2009) explored the effect of brand image on customer loyalty and commitment in China. Michel and Rieunier (2012). Nonprofit brand image and typicality influences on charitable giving. Fruchter et al. (2006) investigated the dynamic production location decisions of a manufacturer of a certain branded product. Recently, there has been a growing interest to use soft computing techniques for marketing planning. Lin and Hsu (2011), for instance, proposed a model based on fuzzy analytical hierarchy process in brand image decision-making.

\section{The proposed model}

In this paper, we present an exploration study to detect important factors influencing car accessory market. The proposed study designs a questionnaire in Likert scale consists of 16 questions, distributes it among 200 experts and analyses it using factor analysis. Cronbach alpha, Kaiser-MeyerOlkin Measure of Sampling Adequacy and Chi-Square are calculated as 0.823, 0.863 and 791, respectively, which validate the overall questionnaire. Table 1 demonstrates the summary of some preliminary statistics. 
Table 1

The summary of basic descriptive statistics

\begin{tabular}{|c|c|c|c|c|c|c|c|c|}
\hline & \multirow{2}{*}{$\begin{array}{c}\mathrm{N} \\
\text { Statistic }\end{array}$} & \multirow{2}{*}{$\begin{array}{c}\text { Range } \\
\text { Statistic } \\
\end{array}$} & \multirow{2}{*}{$\begin{array}{c}\text { Minimum } \\
\text { Statistic } \\
\end{array}$} & \multirow{2}{*}{$\begin{array}{l}\text { Maximum } \\
\text { Statistic }\end{array}$} & \multicolumn{2}{|c|}{ Skewness } & \multicolumn{2}{|c|}{ Kurtosis } \\
\hline & & & & & Statistic & Std. Error & Statistic & Std. Error \\
\hline VAR00001 & 200 & 8.00 & 1.00 & 9.00 & -.859 & .172 & .847 & .342 \\
\hline VAR00002 & 200 & 8.00 & 1.00 & 9.00 & -1.037 & .172 & 1.235 & .342 \\
\hline VAR00003 & 200 & 8.00 & 1.00 & 9.00 & -.795 & .172 & .163 & .342 \\
\hline VAR00004 & 200 & 8.00 & 1.00 & 9.00 & -.776 & .172 & .196 & .342 \\
\hline VAR00005 & 200 & 8.00 & 1.00 & 9.00 & -.562 & .172 & -.564 & .342 \\
\hline VAR00006 & 200 & 8.00 & 1.00 & 9.00 & -.491 & .172 & -.469 & .342 \\
\hline VAR00007 & 200 & 8.00 & 1.00 & 9.00 & -1.006 & .172 & .540 & .342 \\
\hline VAR00008 & 200 & 8.00 & 1.00 & 9.00 & -.634 & .172 & -.222 & .342 \\
\hline VAR00009 & 200 & 8.00 & 1.00 & 9.00 & -.703 & .172 & -.104 & .342 \\
\hline VAR00010 & 200 & 8.00 & 1.00 & 9.00 & -.361 & .172 & -.286 & .342 \\
\hline VAR00011 & 200 & 8.00 & 1.00 & 9.00 & -.047 & .172 & -.332 & .342 \\
\hline VAR00012 & 200 & 8.00 & 1.00 & 9.00 & -.467 & .172 & -.486 & .342 \\
\hline VAR00013 & 200 & 8.00 & 1.00 & 9.00 & -1.447 & .172 & 1.546 & .342 \\
\hline VAR00014 & 200 & 8.00 & 1.00 & 9.00 & -1.050 & .172 & .535 & .342 \\
\hline VAR00015 & 200 & 8.00 & 1.00 & 9.00 & -.457 & .172 & -.455 & .342 \\
\hline VAR00016 & 200 & 8.00 & 1.00 & 9.00 & -.556 & .172 & -.074 & .342 \\
\hline Valid N (listwise) & & & & & & & & \\
\hline
\end{tabular}

Since factor analysis is sensitive to skewness of the variables, we have decided to make some changes on variables 2, 7, 13 and 14 and Table 2 demonstrates the results of our survey.

Table 2

The summary of descriptive statistics after changes on input data

\begin{tabular}{cccccccc}
$\mathrm{N}$ & Range & \multicolumn{2}{c}{ Minimum Maximum } & \multicolumn{2}{c}{ Skewness } & \multicolumn{2}{c}{ Kurtosis } \\
Statistic & Statistic & Statistic & Statistic & Statistic & Std. Error & Statistic & Std. Error \\
\hline 200 & 8.00 & 1.00 & 9.00 & -.859 & .172 & .847 & .342 \\
200 & 8.00 & 1.00 & 9.00 & -.795 & .172 & .163 & .342 \\
200 & 8.00 & 1.00 & 9.00 & -.776 & .172 & .196 & .342 \\
200 & 8.00 & 1.00 & 9.00 & -.562 & .172 & -.564 & .342 \\
200 & 8.00 & 1.00 & 9.00 & -.491 & .172 & -.469 & .342 \\
200 & 8.00 & 1.00 & 9.00 & -.634 & .172 & -.222 & .342 \\
200 & 8.00 & 1.00 & 9.00 & -.703 & .172 & -.104 & .342 \\
200 & 8.00 & 1.00 & 9.00 & -.361 & .172 & -.286 & .342 \\
200 & 8.00 & 1.00 & 9.00 & -.047 & .172 & -.332 & .342 \\
200 & 8.00 & 1.00 & 9.00 & -.467 & .172 & -.486 & .342 \\
200 & 8.00 & 1.00 & 9.00 & -.457 & .172 & -.455 & .342 \\
200 & 8.00 & 1.00 & 9.00 & -.556 & .172 & -.074 & .342 \\
200 & 2.8786 & -2.3040 & .5746 & -.905 & .172 & -.265 & .342 \\
200 & 3.1580 & -2.4037 & .7543 & -.658 & .172 & -.463 & .342 \\
200 & 3.3579 & -2.5353 & .8226 & -.592 & .172 & -.322 & .342 \\
200 & 2.9075 & -1.9936 & .9138 & -.472 & .172 & -.649 & .342 \\
\hline 200 & \multicolumn{7}{c}{} \\
\hline
\end{tabular}

Next, we present principal component analysis based on our survey and Table 3 demonstrates the results of our survey as follows,

Table 3

Total Variance Explained

\begin{tabular}{|c|c|c|c|c|c|c|c|c|c|}
\hline \multirow[t]{2}{*}{ Component } & \multicolumn{2}{|c|}{ Initial Eigenvalues } & & \multicolumn{3}{|c|}{ Extraction Sums of Squared Loadings } & \multicolumn{3}{|c|}{ Rotation Sums of Squared Loadings } \\
\hline & Total & $\%$ of Var. & Cumulative \% & Total & $\%$ of Variance & Cumulative \% & Total & $\%$ of Variance & Cumulative \% \\
\hline 1 & 4.996 & 31.227 & 31.227 & 4.996 & 31.227 & 31.227 & 2.703 & 16.892 & 16.892 \\
\hline 2 & 1.252 & 7.826 & 39.053 & 1.252 & 7.826 & 39.053 & 2.203 & 13.766 & 30.658 \\
\hline 3 & 1.115 & 6.967 & 46.020 & 1.115 & 6.967 & 46.020 & 2.047 & 12.793 & 43.451 \\
\hline 4 & 1.085 & 6.784 & 52.804 & 1.085 & 6.784 & 52.804 & 1.496 & 9.352 & 52.804 \\
\hline 5 & .946 & 5.914 & 58.718 & & & & & & \\
\hline 6 & .928 & 5.800 & 64.517 & & & & & & \\
\hline 7 & .812 & 5.076 & 69.593 & & & & & & \\
\hline 8 & .777 & 4.853 & 74.446 & & & & & & \\
\hline 9 & .707 & 4.416 & 78.862 & & & & & & \\
\hline 10 & .594 & 3.711 & 82.573 & & & & & & \\
\hline 11 & .565 & 3.528 & 86.102 & & & & & & \\
\hline 12 & .529 & 3.308 & 89.410 & & & & & & \\
\hline 13 & .483 & 3.019 & 92.429 & & & & & & \\
\hline 14 & .437 & 2.733 & 95.162 & & & & & & \\
\hline 15 & .415 & 2.594 & 97.757 & & & & & & \\
\hline 16 & .359 & 2.243 & 100.000 & & & & & & \\
\hline
\end{tabular}


Now we can extract the number of important factors using scree plot. Fig. 1 shows the summary of our findings.

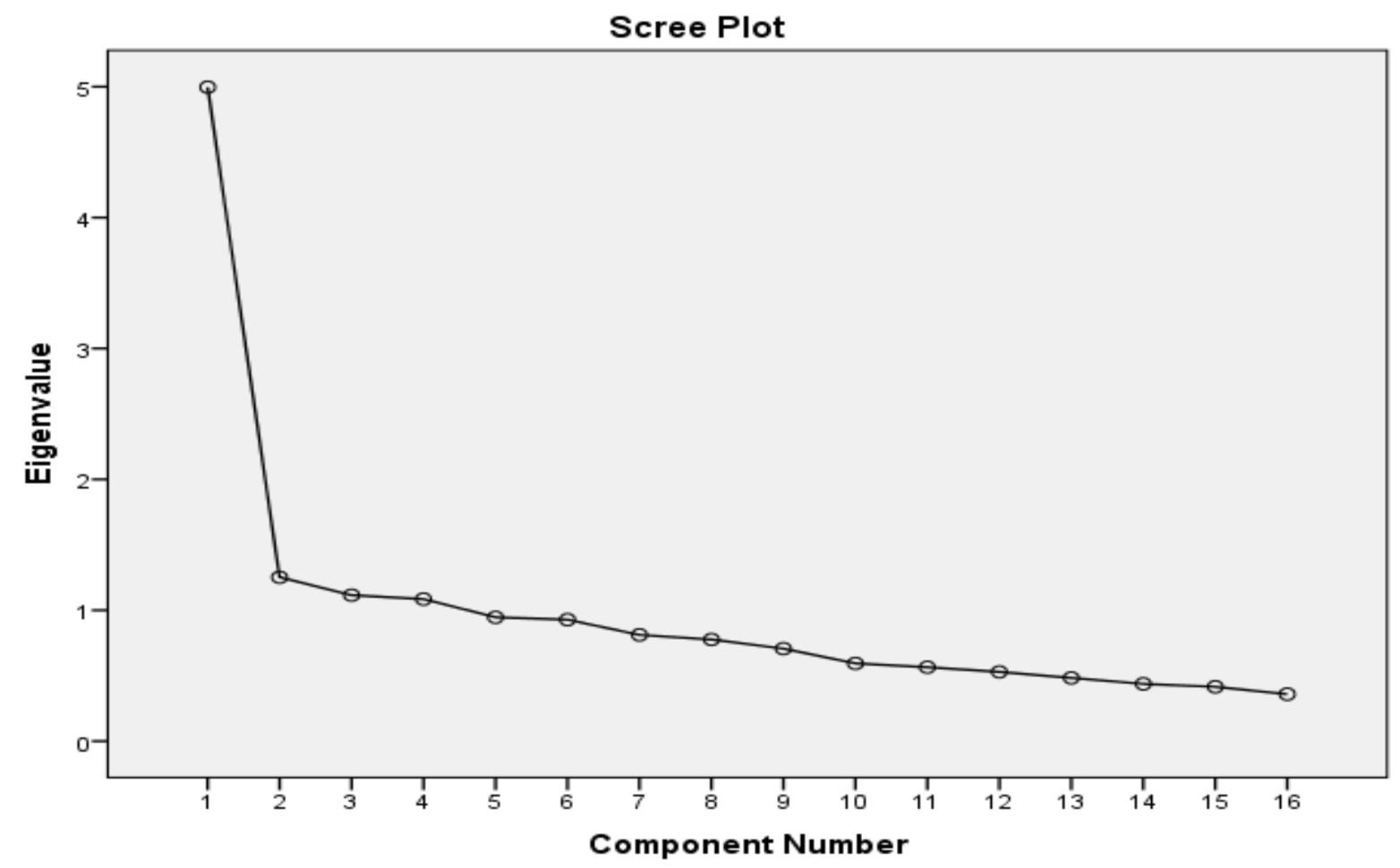

Fig. 1. The summary of Scree plot

As we can observe from the results of Fig. 1, the trend of this figure become smooth after three variables. Therefore, we decide to choose three components.

Table 4

Rotated Component Matrix ${ }^{\mathrm{a}}$

\begin{tabular}{|c|c|c|c|c|}
\hline & \multicolumn{4}{|c|}{ Component } \\
\hline & 1 & 2 & 3 & 4 \\
\hline VAR00003 & .679 & & & \\
\hline VAR00001 & 670 & & & \\
\hline VAR00008 & 659 & & & \\
\hline Normal Score of VAR00002 using Blom's Formula & 628 & & & \\
\hline VAR00010 & .463 & & & .379 \\
\hline VAR00015 & & .748 & & \\
\hline VAR00016 & & .728 & & \\
\hline Normal Score of VAR00014 using Blom's Formula & & .642 & & \\
\hline Normal Score of VAR00013 using Blom's Formula & & .487 & .398 & \\
\hline VAR00005 & & .394 & & \\
\hline VAR00004 & & & .721 & .346 \\
\hline Normal Score of VAR00007 using Blom's Formula & & & 677 & \\
\hline VAR00006 & & & .642 & \\
\hline VAR00012 & & & & .719 \\
\hline VAR00011 & .466 & & & .504 \\
\hline VAR00009 & .398 & & & .455 \\
\hline
\end{tabular}

Extraction Method: Principal Component Analysis. Rotation Method: Varimax with Kaiser Normalization.

a. Rotation converged in 11 iterations. 
Based on the results of Table 4, we present details of our findings on three factors; namely brand capability, brand characteristics and consumers' believe.

\section{The results}

\subsection{The first factor: Brand capability}

The first factor is associated with brand capability, which includes 7 sub-factor and Table 5 shows details the results where brand identification, market share and trade capability are important factors.

\section{Table 5}

The summary of factors associated with brand capability

\begin{tabular}{lllll}
\hline Factor & Weight & Eigenvalue & Variance & Accumulated \\
\hline Brand identification & .679 & 2.703 & 16.892 & 16.892 \\
Market share & .670 & & & \\
Trade capability & .659 & & & \\
Trade value & .628 & & & \\
Strategy on success & .463 & & & \\
Distinguished identity & .466 & & & \\
Product characteristics & .398 & & & \\
\hline
\end{tabular}

\subsection{The second factor: Brand characteristics}

The second factor is associated with brand characteristics, which includes five sub-components.

\section{Table 6}

The summary of factors associated with brand characteristics

\begin{tabular}{lllll}
\hline Accumulated & Variance & Eigenvalue & Weight & Factor \\
\hline Applied colors & .748 & 2.203 & 13.766 & 30.658 \\
Logo & .728 & & & \\
Advertisement & .487 & & & \\
Packaging & .642 & & & \\
Price & .394 & & & \\
\hline
\end{tabular}

Based on the results of Table 6, we can conclude that color plays essential role on brand characteristics followed by logo and packaging.

\subsection{The third factor: Consumers' believes}

The last factor is associated with consumers' believes, which includes four sub-component summarized as follows,

\section{Table 7}

The summary of consumer believes

\begin{tabular}{lllll}
\hline Accumulated & Variance & Eigenvalue & Weight & Factor \\
\hline Level of consumer's trust & .677 & 2.047 & 12.793 & $\mathbf{4 3 . 4 5 1}$ \\
Retaining consumer's believes & .642 & & & \\
Consumer's view & .346 & & & \\
Consumer's perception & .719 & & & \\
\hline
\end{tabular}

Based on the results of Table 7 we can understand that consumer's perception plays an essential role on their belief followed by trust and believes. 


\section{Conclusion}

In this paper, we have presented an empirical investigation to find important factors influencing car accessory market. The proposed study found that three factors influenced this industry, significantly. The first factor is associated with brand capability, which includes 7 sub-factor where brand identification, market share and trade capability are important factors. The second factor has been associated with brand characteristics, which includes five sub-components where color plays essential role on brand characteristics followed by logo and packaging. Finally, the last factor is associated with consumers' believes, which includes four sub-component where that consumer's perception plays an essential role on their belief followed by trust and believes.

\section{References}

Arslan, F. M., \& Altuna, O. K. (2010). The effect of brand extensions on product brand image. Journal of Product \& Brand Management, 19(3), 170-180.

Banerjee, A. (2004). A brand share prediction model based on several disparate sources of data: an empirical model of detergent choice in Mumbai, India. Asia Pacific Journal of Marketing and Logistics, 16(3), 3-22.

Bian, X., \& Moutinho, L. (2011). The role of brand image, product involvement, and knowledge in explaining consumer purchase behaviour of counterfeits: Direct and indirect effects. European Journal of Marketing, 45(1/2), 191-216.

Chien, P. M., Cornwell, T. B., \& Pappu, R. (2011). Sponsorship portfolio as a brand-image creation strategy. Journal of Business Research, 64(2), 142-149.

Fruchter, G. E., Jaffe, E. D., \& Nebenzahl, I. D. (2006). Dynamic brand-image-based production location decisions. Automatica, 42(8), 1371-1380.

$\mathrm{Hu}$, J., Liu, X., Wang, S., \& Yang, Z. (2012). The role of brand image congruity in Chinese consumers' brand preference. Journal of Product \& Brand Management, 21(1), 26-34.

Hsieh, A. T., \& Li, C. K. (2008). The moderating effect of brand image on public relations perception and customer loyalty. Marketing Intelligence \& Planning,26(1), 26-42.

Jo, M. S., Nakamoto, K., \& Nelson, J. E. (2003). The shielding effects of brand image against lower quality countries-of-origin in global manufacturing. Journal of Business Research, 56(8), 637-646.

Lin, L. Z., \& Hsu, T. H. (2011). Designing a model of FANP in brand image decisionmaking. Applied Soft Computing, 11(1), 561-573.

Kort, P. M., Caulkins, J. P., Hartl, R. F., \& Feichtinger, G. (2006). Brand image and brand dilution in the fashion industry. Automatica, 42(8), 1363-1370.

Matthiesen, I. M., \& Phau, I. (2010). Brand image inconsistencies of luxury fashion brands: A buyerseller exchange situation model of Hugo Boss Australia. Journal of Fashion Marketing and Management, 14(2), 202-218.

Michel, G., \& Rieunier, S. (2012). Nonprofit brand image and typicality influences on charitable giving. Journal of Business Research, 65(5), 701-707.

Ogba, I. E., \& Tan, Z. (2009). Exploring the impact of brand image on customer loyalty and commitment in China. Journal of Technology Management in China,4(2), 132-144.

Prayag, G. (2010). Brand image assessment: international visitors' perceptions of Cape Town. Marketing Intelligence \& Planning, 28(4), 462-485.

Rindell, A., Korkman, O., \& Gummerus, J. (2011). The role of brand images in consumer practices: uncovering embedded brand strength. Journal of Product \& Brand Management, 20(6), 440-446.

Roth, M. S. (1995). The effects of culture and socioeconomics on the performance of global brand image strategies. Journal of Marketing Research, 32(2), 163-175.

Sääksjärvi, M., \& Samiee, S. (2011). Relationships among brand identity, brand image and brand preference: differences between cyber and extension retail brands over time. Journal of interactive marketing, 25(3), 169-177. 